\title{
Pragmagramática de es que: El operador de intensificación
}

\author{
Pragmatic grammar of es que: The intensification marker
}

\section{Catalina Fuentes Rodríguez}

\author{
Universidad de Sevilla, Facultad de Filología, Departamento de Lengua Española, \\ Lingüística y Teoría de la Literatura, Sevilla, España. Correo electrónico: cfuentes@us.es
}

\begin{abstract}
En contextos como el discurso parlamentario, donde la intensificación es la estrategia pragmática predominante, es que aparece empleado frecuentemente como focalizador y como operador de intensificación. Esta última función aparece como derivada de la anterior y muestra la interconexión entre planos macroestructurales (focalización, modalidad y argumentación) y tipo discursivo, así como la necesidad de un enfoque multidimensional en el estudio pragmático (Fuentes 2015 [2000]). Para confirmar nuestra hipótesis, contrastamos su empleo con otros modelos textuales, cuyos objetivos comunicativos y registro son claramente distintos. El operador intensificador aparece en textos de mayor cercanía comunicativa, donde la implicación del hablante es mayor, y sobre todo, en contextos polémicos. Conforme avanza la distancia, la formalidad, va desapareciendo su uso.
\end{abstract}

Palabras clave: marcador del discurso, intensificación, discurso parlamentario, focalización, pragmática

In contexts such as parliamentary speech, where intensification is the predominant pragmatic strategy, es que is often employed as a focuser and also as an intensification operator. This last function appears as a derivation the first one and shows the interconnection between macrolevels (focus, modality and argumentation) and the discursive type, as well as the need for a multidimensional approach in the pragmatic study (Fuentes 2015). To confirm this hypothesis, I contrast the use of es que in other textual models whose communication objectives and register are clearly distinct. The intensifier operator appears in texts with greater communicative proximity, where the involvement of the speaker is larger, and particularly in controversial texts. As distance and formality increase, the use of es que disappears.

Key words: discourse marker, intensification, parliamentary discourse, focus, pragmatics 


\section{INTRODUCCIÓN}

Es que es una estructura que en español puede introducir una focalización o actuar como conector (marcador del discurso) introduciendo una justificación. Sin embargo, está desarrollando otras funciones, entre ellas la de operador de intensificación. Documentamos este uso en un tipo discursivo concreto, el discurso parlamentario ${ }^{1}$. Específicamente, hemos trabajado con las sesiones de Plenos y Comisiones del Parlamento Andaluz.

Proponemos un estudio pragmático integral (Fuentes 2013a, 2015): describir el comportamiento sintáctico del elemento, su categorización, y las funciones discursivas que desempeña en conexión con el tipo discursivo elegido ${ }^{2}$. Para ello partimos, en primer lugar, de una descripción de su empleo (valores y frecuencia de uso) en el Parlamento Andaluz ${ }^{3}$, y, en segundo lugar, lo contrastamos con una selección de otras variantes textuales, empleando para ello discursos políticos, mediáticos y científicos, orales y escritos ${ }^{4}$. Estos textos varían en su registro, pasando de lo formal a la coloquialización extrema, lo que nos permite comprobar el grado de extensión de este operador de intensificación y concluir si es un elemento ligado a cierto tipo discursivo, o se emplea en cualquier circunstancia comunicativa en la que el hablante quiera imponer su aserción frente al resto.

Para ver las características del discurso parlamentario consultar, entre otros, van Dijk (2000, 2004, 2005), Ilie (2001, 2003, 2004), Chilton y Schäffner (2002), Núñez Cabezas y Guerrero Salazar (2002), Bayley (2004), Chilton (2004) y Arce Castillo (2006).

2 Este trabajo es fruto de dos proyectos de investigación: P10-HUM 5872 "La perspectiva de género en el lenguaje parlamentario andaluz", financiado por la Junta de Andalucía y Fondos FEDER, y "Macrosintaxis del español actual", financiado por el MICINN FFI 2013-43205-P.

3 Hemos elegido 8 sesiones parlamentarias completas de la VIII Legislatura: http://www.parlamentodeandalucia.es/ webdinamica/portal-ebparlamento/recursosdeinformacion/diariosdesesiones/comisiones.doc

4 - Castilla del Pino, Carlos. 2004. Reflexión, reflexionar, reflexivo. Discurso de entrada en la RAE (7/3/2004): http:// www.rae.es/rae/gestores/gespub000001.nsf/(voAnexos)/archC51A9CDF7A1C1FCCC1257147003A0582/ \$FILE/ castilla.htm (consultado el 1 de agosto de 2013). (CC).

- Gutiérrez Ordóñez, Salvador. 2008. Del arte gramatical a la competencia comunicativa. Discurso de entrada en la RAE (24/2/2008): http://www.rae.es/rae/gestores/gespub000028.nsf/(voanexos)/ archC9558492965F2CAEC12573 F7003F39F7/\$FILE/Discurso\%20Salvador\%20Guti\%C3\%A9rrez.pdf (consultado el 1 de 8 agosto de 2013). (SG). - Iglesias Bango, Manuel. 2004. "Algunas construcciones incidentales con como en español". Actas VI Congreso de Lingüistica General. Santiago de Compostela, España (3-7/5/2004). (MI).

- Medina, Javier. 2013. "Modelos de (des)cortesía verbal en la prensa española: El caso de El Día (Tenerife)". Revista Rilce 29.2: 365-88. (JM).

- Ministerio de Sanidad. Sanidad, Servicios Sociales e Igualdad. Aprobada la Estrategia para la Erradicación de la Violencia contra las Mujeres 2013-2016 (26/7/2013): http://www.lamoncloa.gob.es/ConsejodeMinistros/ Enlaces/260713violenciamujeres.htm (consultado el 1 de agosto de 2013). (MS).

- Narbona Jiménez, Antonio. 2013. "Novedades teóricas en la NGRAE". Orillas 2: 1-16. (AN).

- Príncipe de Asturias. Palabras de S.A.R. el Príncipe de Asturias en la ceremonia de entrega de los Premios Príncipe de Asturias de 2012: http://www.fpa.es/es/sar/discursos/2012.html (consultado el 1 de agosto de 2013). (PA).

- Puértolas, Soledad. 2010. "Aliados. Los personajes secundarios del Quijote". Discurso de entrada en la RAE (21/11/2010): http://www.rae.es/rae/gestores/gespub000028.nsf/(voanexos)/ arch80FAD4CE8E6D24D6C12577E5 003FBB26/\$FILE/Discurso\%20SOLEDAD\%20PUERTOLAS.pdf (consultado el 1 de agosto de 2013). (SP).

- Rajoy, Mariano. Discurso del presidente del Gobierno en su visita a la factoría de General Motors (10/7/2013): http://www.lamoncloa.gob.es/Presidente/Intervenciones/Discursos/2013/prdi20130710.htm (consultado el 1 de agosto de 2013). (R1).

- Rajoy, Mariano. Discurso del presidente del Gobierno en la clausura de la Reunión de Alto Nivel sobre Seguridad Alimentaria (4/4/2013): http://www.lamoncloa.gob.es/Presidente/Intervenciones/Discursos/ 2013/prdi20130404. htm (consultado el 1 de agosto de 2013). (R2). 
Comenzamos con una breve revisión de la caracterización sintáctica de este elemento (sección 2), pasamos a describir su empleo en estructuras de focalización (sección 3), como operador de intensificación (sección 4), y otros valores que encontramos en el corpus (secciones 5 y 6 ), para terminar con un estudio cuantitativo (sección 7), y una comparación con otros tipos discursivos (sección 8). De esta manera, obtenemos una caracterización integral que incluye las funciones discursivas, los tipos de contexto y los discursos en los que aparecen.

\section{Gramática dE ES QUE}

Es que es considerado habitualmente una combinatoria libre de verbo copulativo (es) y conjunción completiva (que). Constituye una estructura ecuacional (Gutiérrez Ordóñez 1986; Herrero 1992) que enlaza dos elementos correferentes como mecanismo de enfatización (Herrero 1992). Algunos (Kovacci 1991) la analizan como una relación atributo-sujeto ${ }^{5}$. Otros investigadores se han detenido en sus funciones discursivas. Para Gili Gaya (1960) aparece en interrogaciones denotando "afirmación exclusiva” en estrategias de oposición. Alcina y Blecua (1983) o Vigara Tauste (1994) lo sitúan entre las expresiones retardatarias o (auto) estimulantes conversacionales. Steel (1991) lo considera en contextos modalizados, donde se emplea para expresar indignación, impaciencia, sarcasmo o atenuación en los mandatos, y lo define como un "adjunct of assertion" (1991: 29). Mulder (1991), por su parte, estudia es que y lo que pasa es que como atenuantes utilizados en la cortesía negativa.

La vitalidad de esta construcción y su empleo aún en construcciones enfatizadas de todo tipo ha hecho que no todos acepten su fijación como marcador, ya que es posible, según ellos, reponer un segmento como cosa, motivo, asunto... elidido (Fernández Leborans 1992) y, por tanto, entenderlo siempre como una estructura "que no constituye un segmento sintáctico sino la unión del verbo copulativo es y la conjunción que, que encabeza una subordinada sustantiva" (RAE 2009: 3483). Esta construcción queda incluida entre las formas de relieve ${ }^{6}$, con la función de introducir una oración como información focal: lo que pasa es que, lo que sucede es que. En el mismo grupo sitúa la RAE los casos de justificaciones y excusas.

En otro lugar, la RAE habla de una subordinada sustantiva usada "para justificar lo que se acaba de decir" (2009: 2797). Empleada en la réplica, justifica la postura del hablante ante lo expuesto por el interlocutor. Bajo el mismo epígrafe, la Real Academia recoge la introducción de preguntas retóricas, pero luego asimila es que a las locuciones conjuntivas o conectores discursivos que introducen una causal explicativa, siempre precedida de una pausa (2009: 3483). Como vemos, la caracterización de esta forma es muy confusa.

\footnotetext{
Cfr. Navas Ruiz (1977), Moreno Cabrera (1982, 1983), Gutiérrez Ordóñez (1986, 1997), Fernández Leborans (1992), Gómez Torrego (1994) y Martínez (1994).

6 Corresponde a las copulativas enfáticas, también llamadas construcciones de relieve, fórmulas de relieve y copulativas perifrásticas. Se resalta uno de sus miembros, y pueden ser de tres tipos: Copulativas enfáticas de relativo: "Eso es lo que ocurrió".

Copulativas de que galicado: “Cómo fue que ocurrió?".

Copulativas enfáticas condicionales: "Si lo hace será porque le gusta".

Las primeras han sido llamadas también perífrasis de relativo, oraciones hendidas, oraciones escindidas y oraciones pseudohendidas. Cuando es toda la oración la que se enfatiza se hace preceder de Lo que pasa es que. La tercera corresponde a las ecuandicionales (Gutiérrez Ordóñez 1997).
} 
En nuestra opinión, es que forma parte de las estructuras ecuacionales (Herrero 1992: 208 y siguientes; Gutiérrez Ordóñez 1997: 37; Fuentes 1997: 238, 1999: 55-56), pero también tiene un uso ya como estructura fijada. En Fuentes (1997) se postula la formación de un conector fijado, es que, cuando aparece en oraciones independientes, introduciendo enunciados completos cuyo contenido se pone de relieve o cuya función argumentativa se destaca ${ }^{7}$. La focalización de todo el enunciado deriva en énfasis de su función argumentativa. Es el introductor de "una justificación argumentativa" (Fuentes 1997: 260). En Fuentes (2009: 157) se habla de es que como conector justificativo. Su presencia hace que el enunciado introducido actúe como argumento del enunciado previo. Exige la presencia de otro enunciado que actúa, así, como conclusión. Es lo que podemos ver en el ejemplo (1):

(1) Es una pena que no esté aquí el Consejero. Es que me gustaría saber qué pensó cuando llegó la Guardia Civil y se lo preguntó allí, personalmente, al Director General de Empleo. Eso me gustaría saberlo (DSPA ${ }^{8} 114,20$, Sr. Loaiza, $\left.\mathrm{PP}^{9}\right)$.

En este trabajo hemos partido de un tipo discursivo concreto, el parlamentario, caracterizado por la imposición de la opinión, y hemos detectado, junto a las funciones de focalizador y conector justificativo, el uso de es que con una función de operador de intensificación. Al ser éste un texto conflictivo, es que se erige en un mecanismo empleado por los parlamentarios para: a) imponer su aserción al otro, y b) conseguir destrozar la imagen y la argumentación del contrario. Al mismo tiempo, sirve para la construcción de la identidad del propio agente discursivo, dentro de su propio endogrupo (ver nuestro trabajo en Fuentes (2013 en prensa)). El valor de intensificación ${ }^{10}$ es más marcado en este tipo de discurso, y por ello es el que resalta de es que, dando paso a la aparición de una función discursiva específica de esta construcción.

Partimos de una descripción de las distintas funciones de es que, empezando por su función como focalizador, que podríamos considerar originaria, centrándonos en el uso como operador de intensificación, que destaca en nuestro corpus, y terminando con un repaso del resto de funciones discursivas de este elemento. Para poder elevar conclusiones interesantes acerca del funcionamiento de esta estructura y su grado de fijación en la lengua actual comparamos los resultados obtenidos con otros tipos discursivos (superestructura en términos de van Dijk (1983)).

Seguimos, de esta forma, la metodología de Lingüística Pragmática expuesta en Fuentes $(2015[2000])^{11}$, en la que el análisis de las funciones micro y

"una estructura ya lexicalizada que introduce un enunciado, enfatizando su contenido. Es un mecanismo informativo de focalización, que proviene del uso para destacar un segmento en una estructura ecuacional (...). Destaca la función argumentativa de un enunciado, lo presenta como argumento, generalmente coorientado" (Fuentes 1997: 261).

8 DSPA: Diario de Sesiones del Parlamento de Andalucía. DSC: Diario de Comisiones. Indicamos página, diputado y partido al que pertenece.

9 Indicamos el partido del parlamentario: PSOE (Partido Socialista Obrero Español), PP (Partido Popular), IU (Izquierda Unida).

10 Para la intensificación ver Portero Muñoz (1997), Briz Gómez (1998) y Albelda Marco (2007).

11 En esta propuesta se considera la necesidad de analizar la microestructura (en este caso la estructura sintáctica es que) en relación con la macroestructura: función cohesiva en el texto, relación con el hablante (enunciación, modalidad) o con el oyente (estructuración informativa, argumentación), así como su superestructura, es decir, la relación con el tipo de discurso. Esto nos proporcionará un análisis integral del elemento. 
macroestructurales se interconecta con el tipo de discurso. En nuestra opinión, es necesario metodológicamente realizar una descripción multidimensional del comportamiento discursivo de las unidades y, al mismo tiempo, comprobar la coexistencia de diferentes funciones de un mismo marcador discursivo (polifuncionalidad). Todo ello debido a la rentabilidad que tienen estas marcas en la estructura informativa y argumentativa del texto. Focalización e intensificación son contenidos que van juntos en el caso de un discurso polémico como es el del Parlamento. Y, como vamos a ver, van también de la mano en una estructura como es que, que comienza en la focalización y deriva a la intensificación, sobre todo en situaciones comunicativas que favorecen el enfrentamiento.

\section{ES QUE FOCALIZADOR}

Como hemos dicho, es que es una estructura que aparece en estructuras hendidas de realce de un segmento. Su función es enlazar el elemento que se focaliza con el resto de la predicación:

(2) Ese enfoque no es que no quepa en nuestra filosofía, en nuestro modo de ver las cosas, no cabe en la Constitución Española, que apuesta por un modelo de Estado social, que incorpora un pacto por la economía social, por la supeditación de toda la riqueza nacional y de la actividad económica al interés general que son incompatibles con esas políticas (DSPA 105, 12, Sr. Martínez Vidal, PSOE).

En el corpus es más frecuente, sin embargo, en otras oraciones cuyo primer segmento (soporte) incluye: a) construcciones de relativo ${ }^{12}$, o b) sustantivos o adjetivos que actúan como encapsuladores (Borreguero 2006; Borreguero y Octavio de Toledo 2007), o etiquetas discursivas (González Ruiz 2009; Izquierdo y González Ruiz 2013). El primer segmento funciona como punto de partida o tema, al que sigue, tras que, el resto de la predicación, que contiene la información nueva que se ofrece ${ }^{13}$. En los textos parlamentarios analizados aparecen ambas construcciones de manera frecuente.

\subsection{Tras un relativo}

La predicación se bifurca en dos partes, separadas por es que, que actúa de nexo predicativo $(A \ldots$ es que $B)$. A es la predicación y $\mathrm{B}$ el objeto de la misma. Esta predicación se presenta como algo consabido, como marco, fondo, una aserción cuya existencia no se discute, a la que sigue el caso concreto (el sujeto) que la cumple.

(3) Miren, a ustedes lo que les escuece de verdad, señor Raynaud y señorías del PP, es que sea un Gobierno socialista el que haya saldado la deuda histórica. Eso es lo que de verdad les molesta (DSPA 105, 13, Sr. Martínez Vidal, PSOE).

La estructura es: hecho general (consabido) - caso particular (nuevo). Este hecho concreto se resalta de forma estratégica. Es decir, se acepta en (3) que algo les

\footnotetext{
2 De ahí que algunos autores, como Moreno Cabrera (1999), lo llamen perífrasis de relativo.

13 Soporte-aporte en Gutiérrez Ordóñez (1997).
} 
escuece y el oyente sólo puede discrepar en qué les escuece. Si el hablante hubiera elegido un enunciado no hendido la aserción completa se sometería a discusión: "les escuece que sea un gobierno...". El hablante habría comprometido su imagen y su credibilidad en esta aserción, que presenta como suya. En la focalización con es que presenta la predicación como conocida por todos ("les escuece algo"), con lo que no es susceptible de ser opinable. Es una manipulación clara, una estrategia argumentativa muy rentable.

Por ello resulta doblemente interesante conocer qué predicaciones aparecen resaltadas. Nos dibujarán la intención argumentativa del hablante, pero también para qué utiliza el parlamentario esta estrategia, ya que es muy frecuente, como veremos más adelante en el estudio cuantitativo. Encontramos entre ellas los siguientes predicados: lo que le interesa, lo que están esperando, lo que está causando, lo que no voy a permitir nunca, lo que verdaderamente me irrita, la valoración que hago de ese informe, lo que he planteado, lo que verdaderamente me duele, lo que me resulta sospechoso, lo que necesita..., lo que hace falta, lo que le pedia..., lo que significa, lo que demuestra, lo que nos parece adecuado, lo que planteamos, lo que sí espero, lo que podemos concluir, lo único que sí matizaría, lo que solicitamos, lo que lamento, lo que sí le pido, lo que pretendemos, lo que no entendemos, lo que confiamos, lo que se entiende.

El hablante resalta un elemento argumentativamente relevante, que fija la línea teórico-argumentativa del texto (a), o bien una predicación evaluativa (b). Veamos casos de ambas funciones:

- a) Focalización y fijación de su función argumentativa o informativa expresada en el segmento precedente: en los casos que siguen encontramos lo que sería pertinente, preámbulo que sitúa el valor informativo del segmento que sigue, o bien lo que le pediría, lo que pretende el Partido Popular, que lo sitúan dentro del diseño argumentativo que realiza el hablante para persuadir a su receptor:

(4) Yo creo que lo que sería pertinente, a estas alturas, es que ustedes dijeran, de una vez, en este Parlamento, cuál es su modelo de servicio público y qué es lo que ustedes piensan hacer (DSPA 105, 37, Sra. Martínez Aguayo, Consejera de Hacienda).

(5) Entonces, lo que le pediría, señora Consejera, es que no nos vuelvan a contar el cuento de las habas, sino que realmente se asuma con seriedad algo que clama al derecho más elemental de las personas que ahí viven (DSPA 105, 42, Sr. Sánchez Gordillo, IU).

(6) Mire usted, lo que pretende el Partido Popular es que no pase lo que ha estado pasando hasta ahora (DSPA 122, 14, Sr. Ramos, PP).

Incluso, como en (7), pone de relieve su función como conclusión (lo que podemos concluir), o se refuerza o legitima la aserción, estableciéndola como conclusión o como admitida por todos (lo que se demuestra en 8).

(7) No tienda usted a mezclarlo todo, porque al final lo que podemos concluir es $q u$ usted pretende sacar el todo por una parte o que lo que pretende es que no nos lleguemos a encontrar (DSPA 133, 40, Sr. Sicilia). 
(8) Señorías, el papel, en este caso no lo aguanta todo. Al final, lo que se demuestra es que el gobierno se limita a publicar papel mojado, porque ni ejecuta y, desde luego, no tiene previsto lo que piensa..., o no va a ejecutar lo que tiene previsto (DSPA 105, 16, Sra. Martín Moya, PP).

Este refuerzo argumentativo lleva hasta violentar la sintaxis. Lo que sería una perífrasis modal (hay que ayudar) se desgaja focalizando un segmento y concediéndole valor predicativo al auxiliar (hay):

(9) Desde las administraciones se ha hecho un buen esfuerzo, así hay que reconocerlo, y lo que hay en este tipo de situaciones es que ayudar, y no tratar de pescar en río revuelto, como siempre hace el Partido Popular (DSPA 115, 35, Sr. Martínez Vidal, PSOE).

- b) Focalización de una evaluación: en (10) se utiliza tras una predicación que verbaliza el rechazo del hablante (lo que no puede ser), y su variante (lo que tampoco es de recibo). Estas construcciones de relativo son muy frecuentes y variadas.

(10) Y mire, ¿qué queremos cambiar, y qué es lo que no puede ser? Pues, lo que no puede ser, por ejemplo, y según se ha dicho en la Cámara de Cuentas, es que el 60\% de las ayudas que deberían haber ido a las PYMES se concentren en cinco grandes empresas. Lo que no puede ser es que el nivel de impuestos que actualmente grava a las empresas en Andalucía, el más alto de España, haga casi imposible generar riqueza y generar empleo. Lo que no puede ser, señorías, es que la deuda de la Junta de Andalucía con las empresas de obras públicas, solamente obras públicas, ascienda ya a más de 700 millones de euros. Lo que tampoco es admisible es que la deuda de la Junta con proveedores sanitarios supere los 946 millones de euros. No se puede admitir que la Junta de Andalucía esté pagando a sus proveedores con 550 días de demora. Y lo que tampoco es de recibo es que la ayuda, y la negativa de la Consejería de Obras Públicas a asumir las ayudas a promotores y compradores que se establecen en el Plan Concertado de Vivienda y Suelo de Andalucía, que han sido eliminadas tras la modificación (DSPA 118, 10, Sr. Nieto, PP).

En otros casos el contenido léxico de adjetivo o de la construcción verbal marca claramente la evaluación: sospechoso, imposible, contradictorio (...) (11-14), incluso la emoción (lo que me faltaba ya (15)).

(11) Por tanto, lo que parece sospechoso, señor García, no es justamente que el propio Servicio Andaluz de Salud haya ido pidiendo la documentación que necesita para una tramitación, sino lo que me resulta sospechoso es que le entren las prisas al Ayuntamiento del Puerto justamente ahora cuando hay una convocatoria de elecciones municipales (DSPA 114, 56, Sra. Montero Cuadrado, Consejera de Salud).

(12) Señorías del Partido Popular, lo que es imposible es que, con la manera ruin y miserable que tienen ustedes de hacer política, alguna vez el pueblo andaluz les dé la confianza (DSPA 114, 72, Sr. Cebrián, PSOE).

(13) Él solamente iba a coordinar los trabajos de emergencia, a solucionar problemas. Pero lo que me resulta patológico, de verdad, es que usted hasta las catástrofes las utilice 
para su provecho (DSPA 105, 49, Sr. Griñán, Presidente de la Junta de Andalucía).

(14) Lo que me parece verdaderamente contradictorio es que, usted, cuando se ha suprimido esta prestación, haya dicho que vamos a entrar en emergencia social por la supresión de una prestación... (DSPA 105, 52, Sr. Arenas, PP).

(15) Señor Presidente, yo asisto a este debate e intervengo como considero procedente. Lo que me faltaba ya es que me diga usted lo que tengo que decir en los debates, si puedo opinar de su debate con el señor Valderas o no (DSPA 105, 50, Sr. Arenas, PP).

De ahí a actuar como marcadores modales hay un paso. Es lo que ocurre con lo que está claro es que (16), o bien con expresiones claramente enunciativas, desplazando el foco de interés al acto de decir: lo que hay que decir, lo que quiere decir (17-18):

(16) Lo que está claro es que el Gobierno español y el andaluz siempre han apostado más por el turismo institucional de Guadalajara, de Cuba o Venezuela, que por su presencia activa en Europa (DSPA 105,26, Sra. Crespo, PP).

(17) En relación con el contenido de esta ley o de este proyecto de ley, lo primero que hay que decir es que, con carácter general, persigue lo que podríamos denominar simplificación, agilización administrativa...; de alguna manera, desburocratizar, valga la expresión, la gestión de la Administración andaluza (DSPA 119, 7, Sr. García Rodríguez, IU).

(18) Señor Presidente, aceptándole la rectificación que me hacía, porque no era mi intención decir que la Administración estuviera por encima de los Gobiernos. Lo que quería decir es que la Administración está obligada, y la función pública, a estar al servicio del conjunto de la ciudadanía por igual, por encima de los Gobiernos y de los partidos que los sostienen, que es la acusación que se está haciendo (DSPA 105, 46, Sr. Valderas, IU).

En estos casos, comienza siendo una estructura libre que progresivamente va adquiriendo una función modal o enunciativa, encontrándonos estadios de semifijación, como los que acabamos de citar.

Es que, como podemos comprobar, es una marca directa del enunciador que refuerza su enunciación, focaliza informaciones o refuerza argumentos.

\subsection{Tras etiqueta discursiva}

La segunda estructura de focalización incluye en el primer segmento un sustantivo o un adjetivo, cuyo contenido abstracto y genérico se entiende en sentido cohesivo, modal o argumentativo. Son etiquetas discursivas o encapsuladores, como hemos dicho. Su función primera pertenece, pues, al plano temático, a la organización y progresión de la información y la argumentación en el texto. En los casos que tratamos aquí el encapsulador actúa como un deíctico catafórico que captura y clasifica bajo una etiqueta el contenido que sigue, estableciendo su rol temático y argumentativo, y su función cohesiva haciendo avanzar la información. Serían 
etiquetas argumentativas o modales, como veremos, que clasifican y catalogan las informaciones que siguen para orientar la interpretación del receptor. Éste, a través de ellas, conoce la importancia y el rol discursivo que desempeñan para su emisor.

Esta etiqueta o encapsulador puede fijar:

a) La función argumentativa y/o informativa dentro del texto ${ }^{14}$

b) El valor modal

c) La función cohesiva

- a) La etiqueta suele corresponder a un elemento orientado argumentativamente: problema supone presentar lo que sigue como contraargumento, como una información que se enfrenta a otra, que actúa en sentido contrario a lo dicho por el interlocutor.

(19) El problema es que no nos fiamos de ustedes. No son un Gobierno de fiar (DSPA 105, 37, Sr. Fuentes Lopera, PP).

En otras ocasiones el mismo término problema no es tanto argumento como evaluación negativa de lo que sigue.

(20) Su capacidad profética, sinceramente, es pésima. Y el problema es que hoy, a diciembre de 2010, estamos peor que en diciembre de 2009 (DSPA 105, 48, Sr. Arenas, PP).

A veces se personaliza la etiqueta (su problema) o aparece con pleno valor léxico, con un complemento:

(21) Mire usted, señor Vázquez, su problema es que usted, en esta intervención, ha mostrado su cara: la cara del rencor, del sectarismo, aparte del mal gusto (DSPA 122, 13, Sr. Ramos, PP).

(22) Al final, señor Griñán, el problema que tienen es que usted está haciendo todo lo contrario de lo que dicen: igual que Zapatero, tal para cual (DSPA 105, 51, Sr. Arenas, PP).

Encontramos también como etiqueta el sustantivo novedad, que presenta la información como no conocida, y otros sustantivos más genéricos como caso, asunto, tema, delito, debate, cuestión, planteamiento...:

(23) Y la novedad del día de hoy es que tampoco quiere que vaya a Écija y a Lora. No me lo ha pedido, estoy esperándolo ahora en la réplica: «No vaya usted a Écija y a Lora» (DSPA 105, 51, Sr. Arenas, PP).

(24) Pero el caso es que hizo mutis por el foro respecto a estos temas en el momento en que ha parecido que pudiera, eventualmente, haber alguna divergencia administrativa,

\footnotetext{
Cfr. Fuentes y Alcaide (2002) sobre la interacción de ambos factores (punto II.1). Estas funciones pueden coaparecer, sobre todo la función cohesiva frente a las otras.
} 
o discrepancia administrativa, en algunos de los ERE gestionados en su momento (DSPA 114, 13, Sr. Gallego Morales, PSOE).

(25) Ustedes saben que ahora, y hemos tenido también aquí, en Andalucía, algún reconocimiento al respecto, la idea es que nunca el museo, ¿eh? -el museo que pretende explicar, pues, monumentos como éste-, nunca entre en conflicto, en rivalidad con el bien que pretende explicar (DSC 507, 9, Sr. Plata, Consejero de Cultura).

- b) La etiqueta tiene valor modal cuando lo que sigue se fija como real, cierto, verdad, lógico o normal:

(26) La realidad es que el 2011 va a ser, o puede ser, tan duro o más que el 2010, a pesar de todos los esfuerzos que se nos ha dicho aquí que se están haciendo (DSPA 111, 22-23, Sr. Vaquero, IU).

(27) Cierto es que la pluviometría de estos días, especialmente los días 6 y 7, pues ha superado todas las previsiones (DSPA 105, 74, Sr. Díaz Trillo, Consejero de Medio Ambiente).

(28) Lo normal es que la votación se realice punto por punto (DSC 507, 27, Sr. Fernández-Viagas, Letrado).

- c) La mera organización cohesiva se percibe cuando el elemento es más genérico:

(29) Y buenas tardes a todas las personas presentes. Lo primero es que no sé si el señor Consejero vive en la Andalucía real o en la Andalucía oficial y virtual que el Partido Socialista se crea, porque viene a informar sobre las ayudas de la empresa, a las empresas, y no dice ni una sola palabra de lo que está investigando la Fiscalía en Andalucía, en ayuda de la Guardia Civil, desde hace casi un año, sobre un nuevo fraude en las ayudas a las empresas en Andalucía concedidas por la Junta, por el Gobierno y, concretamente, supongo que con su conocimiento (DSPA 111, 23, Sra. Oña, PP).

\subsection{Y es que de progresión temática}

Encontramos un uso específico de es que focalizador cuando se combina con la conjunción copulativa $y$. Desarrolla una función específica como estructura de avance o progresión temática. $Y$ da paso a una nueva información, que desarrolla la expresada en el enunciado u oración anterior en una relación temática inclusiva de elemento genérico - elemento específico o concreción. El segmento previo actúa como preámbulo que, por un lado, clasifica y ordena temática y argumentativamente, $\mathrm{y}$, por otro, crea expectativas y atrae la atención del receptor.

En la oración precedente hay un elemento que anuncia catafóricamente una información que se desarrolla luego tras y es que. La estructura sigue actuando como una construcción libre de verbo copulativo y oración sustantiva. El sujeto de la misma está elidido, porque recoge el sintagma u oración previos. Por tanto, se trata de una estructura en solidaridad: elemento catafórico o etiqueta genérica $+y$ (etiqueta) es $q u e+$ elemento concreto. No hay que olvidar que la presentación con un preámbulo 
es otro mecanismo de focalización informativa y de intensificación argumentativa y asertiva.

(30) Yo también creo que le he dado razones también para decirle por qué no al adelanto electoral, y una más poderosa que todas las demás, y es que mi gobierno, señor Valderas, goza de estabilidad suficiente para seguir haciendo propuestas, y además también para hacer que sean aprobadas por esta Cámara (DSPA 118, 43, Sr. Griñán, Presidente de la Junta de Andalucía).

En la primera oración aparece razones..., etiqueta que anuncia y clasifica argumentativamente lo que sigue, una ... reproduce lo anterior: "una razón", y introduce otra oración en que se elide "esta razón" es que... En el siguiente fragmento tenemos como elemento de anuncio aspectos y en el siguiente opinión ("hay otros aspectos... y (el aspecto) es que", "le voy a dar mi opinión y mi opinión es que...”):

(31) Pero es que, además, yo creo que hay otros aspectos muy importantes que me gustaría señalar, y es que crea conciencia en el ciudadano (DSPA 118, 40, Sra. Cózar, PSOE).

(32) ¿Qué me parece? Le voy a dar la opinión que tienen el Consejo de Gobierno y esta Consejera, $y$ es que se está demostrando que este mecanismo es absolutamente ineficaz para atender el caso de crisis grave que sufre el aceite de oliva en relación a los precios (DSPA 118, 63, Sra. Aguilera, Consejera de Agricultura y Pesca).

La etiqueta puede ser más genérica y presentar una variante más sencilla: un sustituto, como algo, que conserva sólo el valor cohesivo. En estos casos el anuncio es claro:

(33) Señorías, quisiera terminar recordando algo que ya he mencionado, y es que uno de los aspectos principales de la cooperación andaluza es la llamada cooperación directa o institucional, por la cual la Junta de Andalucía ejecuta directa o a través de sus organismos autónomos y empresas públicas la mayor parte de los recursos destinados a la cooperación al desarrollo (DSPA 105, 16, Sra. Martín Moya, PP).

(34) Y mire, señoría, hay algo que no podemos pasar por alto de ninguna manera, $y$ es que hay una clara discriminación entre los agentes de la cooperación y las ONG. Digamos que los de ustedes, las institucionales, y las ONG. Y es que resulta, y es que resulta, que al final se trata a las instituciones con una manga ancha que, desde luego, resulta vergonzosa, y a las ONG se les obstaculiza su labor hasta tal punto que a veces no pueden desarrollarla (DSPA 105, 23, Sra. Martín Moya, PP).

\section{ES QUE INTENSIFICADOR}

Encontramos en los Diarios de Sesiones un empleo más abundante de es que enfatizando un enunciado completo, resaltando toda la información. Sintácticamente, supone un paso más en la fijación de la estructura de focalización. Es que se convierte en un marcador de todo el enunciado en el plano informativo y argumentativo. Ya no 
es una estructura libre. Frente al conector justificativo (Martín Zorraquino y Portolés 1999; Briz Gómez, Pons y Portolés 2008-2015; Fuentes 2009), que el receptor descodifica como "la prueba es que..." (ver sección 5), aquí se interpreta como "lo que digo es muy relevante, desde mi punto de vista".

(35) Verá, señora Crespo, cuando el señor Arenas fue Ministro del Gobierno de España se produjeron muchas decisiones que no fueron positivas para Andalucía, pero dos de manera decisiva en materia de Unión Europea. La primera fue que se desviaron 4.000 millones de Fondos de Cohesión que correspondían a Andalucía, y que se derivaron a otras comunidades autónomas de España, y, en segundo lugar, que, siendo el señor Arenas Ministro de España y José María Aznar Presidente, se firmó el acuerdo con Marruecos para importar frutas y hortalizas, señora Crespo. Por favor, es que no son ustedes un partido sin historia (DSPA 115, 30, Sra. Moreno Ruiz, Consejera de Presidencia).

Podemos ver claramente su estatus como operador y no conector (Fuentes 2003, 2009), ya que no necesita la presencia de un enunciado previo. Su campo de actuación queda limitado al enunciado en el que aparece. Refuerza esa aserción, y no la liga a la anterior. Con ello intensifica el argumento que se quiere presentar y esgrimir ante los otros ${ }^{15}$.

Es que marca la fuerza argumentativa (Ducrot 1984; Fuentes y Alcaide 2002) que el hablante concede a lo dicho en el enunciado. Este puede ser declarativo o interrogativo. El hablante refuerza argumentos propios o contraargumentos que desacreditan las tesis del contrario. Por ello es muy utilizado en el contexto parlamentario, caracterizado por el discurso polémico (van Dijk 2000, 2002, 2004; Núñez Cabezas y Guerrero Salazar 2002; Bayley 2004; Chilton 2004; Arce Castillo 2006; Blas Arroyo 2011, entre otros). Veamos sus distribuciones.

- a) Lo encontramos reforzando una aserción, que actúa en ocasiones como conclusión de lo precedente.

(36) En octubre de 2010, en la página web del PP se puede ver: «El Partido Popular pedirá a los ayuntamientos y en el Parlamento andaluz mantenimiento del plan Proteja en el 2011». Antes era una trampa, una vergüenza, y ahora piden su mantenimiento. Es que llegan tarde a todo, como la defensa de las políticas sociales, con los pensionistas, con todo (DSPA 117, 44, Sr. Martínez Vidal, PSOE).

- b) Puede introducir un argumento que se resalta, ya sea coorientado o antiorientado.

- b.1) Coorientado: es frecuente su aparición con otros conectores $(y, o$, si, porque, pero...). En (37) aparece junto con un pero enfático, explicitando claramente esa intensificación del decir (hay más). Introduce un argumento que supera en fuerza lo anterior:

15 En este caso, además, se combina con otro elemento de fuerza: por favor. Puede ser suprimible, aunque se perdería en fuerza argumentativa. 
(37) Los ayuntamientos poniendo suelo gratis a la Junta de Andalucía, suelo para equipamientos y servicios; ustedes vendiéndoselo a empresas públicas, y ahora también a particulares. Pero es que hay más: ustedes incumpliendo un año sí y otro también, un cuatrienio sí y otro cuatrienio también, los planes de construcción de viviendas sociales, y ahora le endosan suelos a EPSA. ¡Pero si son ustedes incapaces de cumplir con el programa de construcción de VPO! (DSPA 105 14, Sr. Martínez Vidal, PSOE).

Un caso específico es su combinatoria con otro conector argumentativo: si..., ya sea el si condicional o el interrogativo indirecto. En ambos casos el argumento se presenta como hipotético, pero se refuerza (la condición o el contenido de la pregunta):

(38) Investíguelo usted, si es que tiene algún concepto de la ética, que no dudo que lo tenga (DSPA 118, 54, Sra. Oña, PP).

(39) Le rogaría que me dijera dónde. O si es que va a aparecer, porque el Grupo Socialista ha metido una enmienda. No sería lo mismo (DSPA 115, 73, Sr. Castro, IU).

Podemos encontrarlo también con el si independiente replicativo (Porroche 1998; Montolío 1999), que aparece en un diálogo contraponiéndose a lo dicho por el otro interlocutor, o al propio estado de cosas que hace prever el contexto ${ }^{16}$. Porroche ve siempre en es que este valor replicativo. Sin embargo, no siempre es tan claro, aunque sí conserva el valor de controversia cuando aparece dentro del discurso extenso del parlamentario como reforzador del argumento propio frente al del grupo contrario:

(40) La empresa malagueña Mayoral ha facturado, en el 2010, 210 millones de euros, con un $63 \%$ fuera de España. Si es que hay ejemplos fundamentales a lo largo y a lo ancho de toda Andalucía. Tenemos 4.000 empresas, esto no es flor de un día. Se lo dije el otro día: el aceite apenas representa el 9\% de nuestras exportaciones (DSPA 114, 99, Sr. Núñez, PSOE).

Si da paso a un argumento relevante, dotado de fuerza argumentativa, que parece oponerse a una posición distinta del interlocutor. Es que refuerza esa aserción. Se trata, pues, de dos enfatizadores de argumentos, aunque si lo sitúa en un contexto de contraargumentación. Estos dos marcadores pueden aparecer reforzados por un tercero, pero, que introduce, además, una contrargumentación.

(41) ¿Cómo que la misma proposición que ustedes traen aquí el PSOE la rechaza en Madrid? Que es quien tiene que decidir, porque dice: «Instar al Gobierno de Madrid para que...» Pero si es que en Madrid la acaban de rechazar hace dos días, puede usted mirar el periódico público y puede usted mirar el Boletín de las Cortes. Y, hace un año, lo mismo (DSPA 118, 100, Sr. Sánchez Gordillo, IU).

Según Montolío "las cláusulas con si de valor refutativo sirven tanto para recordar una premisa compartida que el interlocutor parece haber olvidado (...) como para introducir una información nueva, que resulta desconocida por aquél (...), como, muy especialmente - puesto que esta parece la función más frecuente- para corregir una presuposición inadecuada". Se podrían parafrasear por: "si... ¿por qué has dicho lo anterior?" (1999: 57). 
Como podemos comprobar, es que actúa como un reforzador argumentativo, lo que contradice la afirmación de Montolío de que "la introducción de es que suaviza o mitiga el carácter refutativo de la estructura" (1999: 56). En estos casos, considerar $s i$ introductor de una oración condicional con la apódosis elidida (interpretación que ella sostiene) es difícil, incluso en el plano enunciativo (si... ¿por qué sostiene lo contrario?): "si ya no da para más la cera que arde, ¿por qué sigue hablando?”, "si está hecha, ¿por qué me pide que la haga?”:

(42) Porque ustedes vuelven a ver el tema de tramas, de tramas sobre un $1 \%$. Mire, señoría, si es que ya no da para más la cera que arde. Se lo digo. Se lo ha dicho la Consejera y yo se lo reitero: no da para más, sencillamente porque la jueza tiene toda la información (DSPA 121,61, Sr. Recio, Consejero de Empleo).

(43) Señor Fuentes Lopera, yo le podría, simplemente, decir: «Bueno, le aprobamos la enmienda», pero es que ya está hecha. Reconózcamelo, si está hecha, si es que la enmienda... Usted me pide evaluar y revisar, en su caso, el Plan Estratégico de Internacionalización, y yo le digo que el 20 de diciembre de 2010, en el BOJA, hay una orden por la que se establece y regula la comisión de seguimiento y evaluación del Plan Estratégico (DSPA 114, 100, Sr. Núñez Roldán, PSOE).

En nuestra opinión, la entonación como enunciado completo, que termina en cadencia, no hace necesaria ni previsible la apódosis. Creemos, por tanto, que si actúa como un marcador argumentativo y es que como un operador de refuerzo argumentativo.

- b.2) Antiorientado:

(44) Y en Andalucía tenemos que estar especialmente preocupados, porque yo recuerdo que estuvimos con el señor Griñán, Diego Valderas y yo estuvimos con el señor Griñán cuando hablamos de, ante la PAC, cuál era la versión de Andalucía, qué le interesaba a Andalucía defender, y se hablaba de tres pilares: la dehesa, el olivar y el regadío. Pero es que este modelo es particularmente, al quitar los referentes históricos, es particularmente dañino con el olivar. Con esta medida el olivar andaluz no lo aguanta, pero es que el regadío que crea 200.000 empleos tampoco (DSPA 133, 18, Sr. Sánchez Gordillo, IU).

Este contexto de intensificación asertiva aparece de forma clara cuando se opone un argumento a otro que aparece rechazado. Es una estrategia por litotes. Por ello es frecuente encontrarlo en estructuras No es que A, es que B. Es que puede aparecer enfatizando a ambos segmentos (45), o a uno de ellos. Puede ser el segmento que se desautoriza y que sirve de fondo para presentar el que el político considera más relevante. La estructura ahora es No es que $A$, (sino) $B$ (46). O acompaña al argumento resaltado, aquél que el hablante destaca, o hacia donde va la orientación argumentativa, en un contexto polémico, de contraargumentación. En este sentido puede aparecer tras el argumento negado: No A, es que B (47):

(45) ¿Porque sabe, señora Oña, qué pasaría si se aprueba esa petición? Que se declararían nulas, se anularían todas las ayudas, señoría, que en un $99 \%$ no es que sean legales, que lo son, es que se las merecen unos trabajadores que han pasado muchos 
años trabajando, ganando esas ayudas que ha concedido de forma legal el Gobierno de la Junta de Andalucía, señoría (DSPA 118, 83, Sra. Navarro, Consejera de Igualdad).

(46) No es que no se contabilice, usted lo sabe, el endeudamiento, que se contabiliza todo, sino que no se aplican al cálculo del objetivo de estabilidad aquellas empresas que tienen ingresos de mercado (DSPA 105, 12, Sr. Martínez Vidal, PSOE).

(47) Ya no se trata de que consideraran los 51.000 millones de 1995 como una auténtica irresponsabilidad, de que en 1996, nada más y nada menos que el señor Arenas calificara la deuda histórica de folletín electoral, de que en ese año se resistieran a pagar de forma contumaz los 20.000 millones de pesetas ya acordados por el Gobierno de Felipe González. Es que el señor Rajoy, lisa y llanamente, negó la existencia de la deuda histórica (DSPA 105,13, Sr. Martínez Vidal, PSOE).

Ésta es una estrategia muy frecuente en el discurso parlamentario. Encontramos 19 ocurrencias en 8 diarios.

La interrogación es otra marca formal para introducir contraargumentos que se resaltan. Se trata de interrogaciones retóricas (Escandell 1999; Burguera 2009), es decir, enunciados emotivos que muestran la postura de rechazo del hablante. En este contexto es frecuente su coaparición con es que:

(48) ¿Es que acaso, señora Navarro, no existen comisionistas, y alguno muy cercano a la élite del Partido Socialista? ¿No existen comisionistas que se están llevando porcentajes elevadísimos que les corresponden a los trabajadores andaluces? ¿Es que no han pagado ustedes comisiones, como se ha podido demostrar también esta mañana? (DSPA 118, 86, Sra. Oña, PP).

La interrogación refuerza el valor negativo o refutativo del enunciado. Sucede igual cuando aparece como una alternativa a través de una interrogación que funciona como negación:

(49) Por tanto, en conclusión, se ha aprovechado, pero no se ha aprovechado lo suficiente. ¿O es que la agricultura y la ganadería no tienen aún graves problemas en cuestión de costes superiores, problemas de bajadas de renta al agricultor, de relevo generacional, problemas de renovación de estructuras, de unificación de la oferta o de comercialización, graves problemas, señora Consejera? (DSPA 105, 25, Sra. Crespo, PP).

El valor focalizador actúa como procedimiento de fuerza argumentativa. Lo que se destaca o intensifica aparece potenciado como argumento. Información y argumentación (intensificación) se unen en este caso de discurso polémico.

\section{ES QUE JUSTIFICATIVO}

Junto a los usos como enfatizador e intensificador, es que puede aparecer con otras funciones. Una de ellas es la de conector argumentativo ${ }^{17}$ que introduce una

17 Sobre los conectores o marcadores del discurso en español hay una producción ingente. Entre las obras globales que deben consultarse destacamos algunas: Fuentes Rodríguez (1987, 1996, 2009), Martín Zorraquino y Montolío 
justificación de lo precedente. La RAE (2009) lo relaciona, como dijimos en la sección 2, con las causales explicativas. Podríamos decir que introduce una causal de la enunciación, una explicación del decir, de la actividad enunciativa del hablante: "lo digo porque...", o "la prueba de que lo que digo es cierto es que...". En Fuentes (2009) se analiza de este modo, pero habría que aclarar que su distribución es más propia de una conjunción que de un marcador discursivo, ya que tiene posición fija, sin libertad combinatoria, y no aparece entre pausas ${ }^{18}$. Su función conectiva es clara, ya que exige un segmento precedente que justificar, o una situación contextual que exija una explicación verbal. Con todo, es una forma que aparece (Fuentes 1997) frecuentemente en el discurso dialógico, y sobre todo en la modalidad coloquial, pero que en el discurso formal no es tan abundante. En el fragmento siguiente introduce una justificación del acto de habla precedente (una recriminación en 50, una explicación en 51):

(50) ¿Ya no les importan a ustedes las rentabilidades de Agesa? Es que eso fue lo que ustedes defendieron para quedarse con Agesa, a cambio de la deuda histórica (DSPA 115, 14, Sr. Martínez Vidal, PSOE).

(51) ¿Qué es lo que dice la sentencia? La sentencia, y nosotros no estamos de acuerdo, la acatamos, pero vamos a recurrir. Es que no se ha hecho el proyecto sólo de esos dos kilómetros, señoría, donde prácticamente están terminadas las obras, prácticamente, que falta mobiliario, que faltan algunas obras de electrificación, pero prácticamente las obras están terminadas (DSPA 115, 54, Sra. Cruz Villalón, Consejera Obras Públicas y Vivienda).

En (52) sigue a no porque..., estableciendo un paralelismo con el valor causal de la conjunción porque:

(52) No vuelva a decir, señor Consejero -y se lo pido, porque ahora usted me va a replicar con estas cosas-, que estamos poniendo en peligro esos ERE, que estamos poniendo en peligro las ayudas europeas, porque la Oficina Antifraude de la Unión Europea va a investigar esas ayudas. Pero no porque el Partido Popular lo diga. Es que le ha traspasado las diligencias la Guardia Civil, y ustedes tendrán que responder por qué, durante cuatro años, perdón, por qué, durante tres años, en esos incentivos, sus servicios de inspección no han actuado (DSPA 114, 21, Sr. Loaiza, PP).

Es que lleva tan asociado ese valor justificativo que es frecuente encontrarlo en el discurso repetido: el hablante mantiene la forma es que para reproducir la función de excusa o justificación que aporta. El elemento, pues, es el indicador de dicho valor argumentativo.

(53) Decía el portavoz del Grupo Socialista: «Es que es muy poco tiempo, desde junio hasta ahora, muy poco tiempo» (DSPA 118, 69, Sra. Crespo, PP).

(1998), Pons (1998), Portolés (1998), Martín Zorraquino y Portolés (1999), Montolío (2000), Domínguez García (2007), Garcés (2008), Loureda y Acín (2010), entre otros.

18 Ver las características que se citan como prototípicas para estos marcadores del discurso: Fuentes Rodríguez (1987, 1996, 2009), Fraser (1990, 1996, 1999, 2006), Pons (1998), Portolés (1998), Martín Zorraquino y Portolés (1999). 
El conector justificativo no es tan usado en las sesiones parlamentarias. A pesar de ser un entorno oral y conflictivo, no parece albergar muchas justificaciones. Estas parecen más frecuentes en contextos dialógicos de escasa formalidad.

\section{ESTRUCTURAS FIJADAS}

Situamos en un punto aparte las estructuras más fijadas. Se trata de combinatorias que se van haciendo frecuentes en el uso y, unas más que otras, se hallan en un proceso de gramaticalización que las llevará, previsiblemente, a convertirse en conectores u operadores modales o enunciativos. Del primer caso podemos citar $l o$ que pasa es que (Fuentes 2009) o lo que ocurre es que. Estas formas pueden todavía recibir variaciones en sus formas verbales, pero se va viendo cada vez más avanzado el proceso de fijación en lo que pasa es que, que introduce un contraargumento. En el siguiente caso llega incluso a interrumpir la estructura sintáctica.

(54) Las distintas PAC y sus reformas han sido siempre neoliberales. Esta lo que pasa es que es, en este momento en que el capitalismo se ha quitado la careta, el colmo de la desvergüenza (DSPA 133, 28, Sr. Sánchez Gordillo, IU).

Como variante que actúa de manera cercana a un operador modal encontramos lo cierto es que o la verdad es que. Antes habíamos hablado de otras construcciones libres como lo que está claro es que..., ilustrando su tendencia a actuar en estos planos modal y enunciativo:

(55) Y lo cierto es que este documento, en su página 13, dice con toda claridad que el primer elemento del nuevo régimen de ayudas sería una ayuda común de base a la agricultura concebida como una ayuda uniforme, por superficie agraria útil, de cuantía reducida aplicable por igual a todos los agricultores que ejerzan su actividad.

Señora consejera, por mucho que usted raje después, de que este documento salga del Ministerio de Medio Ambiente Rural y Marino, lo cierto es que ya España se ha posicionado porque el Gobierno posiciona a España (...).

Y lo cierto es que habrá que reconocerle -lo cierto es que yo no oí sus declaraciones, no tengo por qué dudar de que las hiciera, no tengo por qué dudarlo-, pero lo cierto es $q u e$, una vez que se ha metido la pata en Europa, es muy difícil sacarla, y el Gobierno español metió la pata porque se erigió en el gran defensor de la «tasa plana», y de esa situación o de esa posición estamos hoy recogiendo los lodos correspondientes (DSPA 133, 30, Sra. García Pelayo, PP).

(56) La verdad es que es el primer gran retroceso en 15 años del dinero que la Junta de Andalucía destina a cooperación internacional (DSPA 105,18, Sr. Mariscal, IU).

\section{ESTUDio CUANTITATIVO}

En el siguiente cuadro recogemos la frecuencia de uso de es que en las Sesiones del Parlamento Andaluz analizadas, diferenciando sus funciones discursivas. Podemos ver su frecuencia desigual, lo que nos da una idea de la rentabilidad que tiene para el político que la emplea. Está claro que las funciones más importantes son 
la focalización, bien de un segmento o de todo el enunciado, es decir, el uso como estructura libre o como operador intensificador. Si bien la primera función es la que tradicionalmente se considera adjudicada a es que y es la más frecuente en algunos diarios $(117,118,119,121,133)$, la de operador intensificador de todo lo dicho, ya sea un argumento coorientado o antiorientado, es igual de frecuente en otras sesiones $(105,111,114)$. Lo vemos en la tabla y el gráfico siguientes:

Tabla 1:

\begin{tabular}{|c|c|c|c|c|c|c|c|c|}
\hline & 105 & 111 & 114 & 117 & 118 & 119 & 121 & 133 \\
\hline $\begin{array}{l}\text { Estructura libre } \\
\text { de enfatización }\end{array}$ & $\begin{array}{c}40 / \\
43,01 \%\end{array}$ & $\begin{array}{c}19 / \\
50 \%\end{array}$ & $\begin{array}{c}45 / \\
43,68 \%\end{array}$ & $\begin{array}{c}24 / \\
57,14 \%\end{array}$ & $\begin{array}{c}58 / \\
48,33 \%\end{array}$ & $\begin{array}{c}29 / \\
55,76 \%\end{array}$ & $\begin{array}{c}23 / \\
44,23 \%\end{array}$ & $\begin{array}{c}22 / \\
52,38 \%\end{array}$ \\
\hline $\begin{array}{l}\text { Conector } \\
\text { justificativo }\end{array}$ & $\begin{array}{c}2 / \\
2,15 \%\end{array}$ & 0 & $\begin{array}{c}5 / \\
4,85 \%\end{array}$ & 0 & $\begin{array}{c}2 / \\
1,66 \%\end{array}$ & $\begin{array}{c}1 \\
(\mathrm{y} \text { es que }) / \\
1,92 \%\end{array}$ & $\begin{array}{c}2 \\
(1 \text { de y es que }) / \\
3,84 \%\end{array}$ & $\begin{array}{c}1 \\
(\mathrm{y} \text { es que) } \\
2,38 \%\end{array}$ \\
\hline $\begin{array}{l}\text { Operador } \\
\text { intensificador }\end{array}$ & $\begin{array}{c}41 / \\
44,08 \%\end{array}$ & $\begin{array}{c}17 / \\
44,73 \%\end{array}$ & $\begin{array}{c}45 / \\
43,68 \%\end{array}$ & $\begin{array}{c}16 / \\
38,09 \%\end{array}$ & $\begin{array}{c}50 / \\
41,66 \%\end{array}$ & $\begin{array}{c}15 / \\
28,84 \%\end{array}$ & $\begin{array}{c}17 / \\
32,69 \%\end{array}$ & $\begin{array}{c}17 / \\
40,47 \%\end{array}$ \\
\hline $\begin{array}{l}\text { Forma fijada } \\
\text { modal: } \\
\text { la verdad es que }\end{array}$ & $\begin{array}{c}7 / \\
7,52 \%\end{array}$ & $\begin{array}{c}1 / \\
2,63 \%\end{array}$ & $\begin{array}{c}5 / \\
4,85 \%\end{array}$ & & $\begin{array}{c}7 / \\
5,83 \%\end{array}$ & $\begin{array}{c}4 / \\
7,69 \%\end{array}$ & $\begin{array}{c}8 / \\
15,38 \%\end{array}$ & \\
\hline $\begin{array}{l}\text { Forma fijada } \\
\text { conector: } \\
\text { lo que pasa } \\
\text { (ocurre) es que }\end{array}$ & $\begin{array}{c}3 / \\
3,22 \%\end{array}$ & $\begin{array}{c}1 / \\
2,63 \%\end{array}$ & $\begin{array}{c}3 / \\
2,91 \%\end{array}$ & $\begin{array}{c}2 / \\
4,76 \%\end{array}$ & $\begin{array}{c}3 / \\
2,5 \%\end{array}$ & $\begin{array}{c}3 / \\
5,76 \%\end{array}$ & $\begin{array}{c}2 / \\
3,84 \%\end{array}$ & $\begin{array}{c}2 / \\
4,76 \%\end{array}$ \\
\hline TOTAL & 93 & 38 & 103 & 42 & 120 & 52 & 52 & 42 \\
\hline
\end{tabular}

\section{Gráfico 1:}

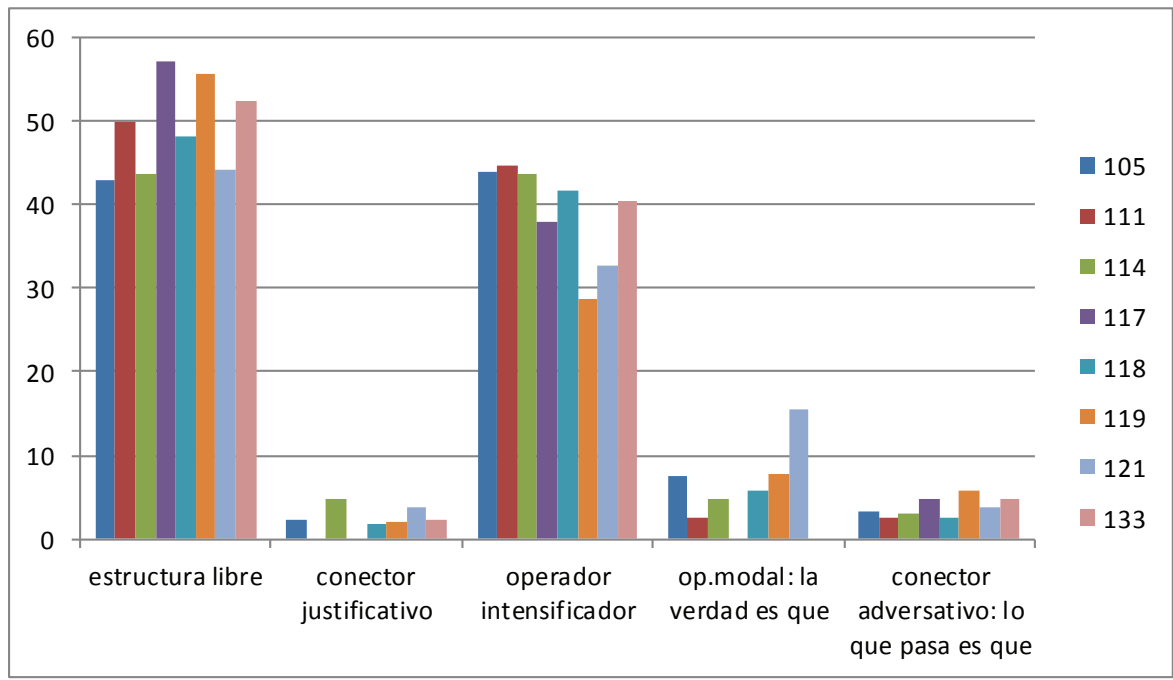


Queda claro que en el discurso parlamentario la función intensificadora es la más frecuente, ya sea expresada por la focalización como estructura libre o por el operador intensificador. En ambos casos el hecho de resaltar una información va dirigido a conseguir una intensificación de la argumentación propia y presentar el discurso como asertivo, brillante, y al hablante como seguro de lo que dice. La relevancia de estas funciones está justificada por el carácter polémico del discurso parlamentario y su objetivo comunicativo: defender la aserción propia frente a los otros.

\section{VARIACIÓN TIPOLÓGICA}

Para confirmar esta hipótesis hemos elegido otro corpus con variación tipológica ${ }^{19}$. En concreto, dos programas televisivos, uno de entrevista, más limitado interactivamente (la entrevista a Felipe González en Salvados de marzo de 2012, texto FG en adelante) y un programa completo de Sálvame del 3 de febrero de 2010 (SV). Estos dos textos orales se confrontan con discursos más formales: textos concepcionalmente escritos aunque transmitidos de forma oral: hemos elegido el discurso de entrada en la RAE de Carlos Castilla del Pino (CC), el de Soledad Puértolas (SP), el de Salvador Gutiérrez Ordóñez (SG); dos discursos del Presidente Rajoy (R1, R2), y otro del Príncipe de Asturias (PA). Entre los textos escritos elegimos una comunicación de prensa del Ministerio de Sanidad (MS) y tres artículos científicos: corresponden a trabajos de Antonio Narbona (AN), Javier Medina (JM) y Manuel Iglesias Bango (MI), todos ellos con un alto grado de formalidad, y producidos entre 2004 y 2013. Los resultados son muy llamativos. Los mostramos en la tabla siguiente:

Tabla 2:

\begin{tabular}{|l|c|c|c|c|c|c|c|c|c|c|c|c|}
\hline & FG & SV & CC & SP & SG & R1 & R2 & MS & PA & AN & JM & MI \\
\hline Estructura focalizadora & 6 & 13 & 0 & 0 & 0 & 0 & 0 & 0 & 0 & 0 & 0 & 0 \\
\hline Conector justificativo & 1 & 8 & 1 & 3 & 0 & 0 & 0 & 0 & 0 & 0 & 0 & 0 \\
\hline Operador intensificador & 7 & 110 & 3 & 0 & 0 & 0 & 0 & 0 & 0 & 0 & 1 & 0 \\
\hline $\begin{array}{l}\text { Modal: la verdad es que, } \\
\text { lo cierto es que }\end{array}$ & 2 & 12 & 0 & 2 & 0 & 0 & 0 & 0 & 0 & 0 & 0 & 0 \\
\hline $\begin{array}{l}\text { Conector: lo que pasa } \\
\text { es que }\end{array}$ & 0 & 8 & 0 & 0 & 0 & 1 & 0 & 0 & 0 & 0 & 0 & 0 \\
\hline
\end{tabular}

Destaca el uso como intensificador en los programas de TV, de carácter dialógico, y sobre todo aquellos en los que hay una conversación, o un polílogo que intenta imitar la conversación familiar, aunque sea un producto mediático (SV). En los casos más formales, la ausencia de es que es llamativa. Sólo encontramos un caso de conector de contraargumentación (lo que pasa es que), en uno de los discursos

\footnotetext{
Ver nota 2.
} 
de Rajoy, un si es que en el texto de Javier Medina, para enfatizar una hipótesis, y varios es que en el caso del discurso de Soledad Puértolas y Carlos Castilla del Pino. Habría que destacar que en el discurso de la primera encontramos dos casos de lo cierto es que, y tres de y es que, abriendo el camino a un nuevo párrafo en el que se introduce la justificación de lo anterior. Este uso, curiosamente, es recriminado por la Fundeu, que aconseja recurrir a otro conector como porque o ya que (http://www.fundeu.es/recomendacion/y-es-que-154/). Sin embargo, como vemos, es una estrategia de avance temático rentable. En el de Carlos Castilla del Pino hay tres casos de intensificador (uno en interrogativo y dos con si es que), y un conector justificativo. Podría objetarse que los textos son de extensión desigual, pero esto sólo nos haría relativizar su frecuencia, pero no explica su falta de aparición en los textos formales. En éstos el uso de operador de intensificación es nulo y sólo encontramos combinatorias modales (lo cierto es que), conectores de oposición (lo que pasa es $q u e)$ o conectores justificativos. La focalización y la intensificación parecen ligadas a una voluntad clara del hablante de manifestar su presencia en el texto. Están más ligados al lenguaje de la valoración, lo que abre una nueva vía de estudio que explorar.

\section{CONClusiones}

En el lenguaje parlamentario, tipo discursivo marcado por la intensificación ${ }^{20}$, hemos asistido al uso de es que para este cometido, y esto nos ha hecho ver su empleo en diferentes distribuciones, poniendo en juego diversos planos discursivos. Este estudio lingüístico-pragmático contextualizado en un tipo discursivo nos ha hecho comprobar la extensión de funciones sintácticas de esta estructura, así como comprobar la necesidad metodológica de aplicar un enfoque multidimensional.

Es que es parte de una estructura de focalización y un conector justificativo. Deriva a un operador, intensificador o marcador de fuerza argumentativa, cuando introduce enunciados cuyo valor destaca. $\mathrm{O}$ forma parte de estructuras fijadas: un conector, $l o$ que pasa es que (menos gramaticalizado está lo que ocurre es que), o un operador: la verdad es que (menos gramaticalizados: lo cierto es que, lo lógico es que...).

Tabla 3:

\begin{tabular}{|c|c|c|}
\hline \multicolumn{3}{|c|}{ Es que } \\
\hline & $\downarrow$ & $\downarrow$ \\
\hline \multicolumn{2}{|c|}{$\begin{array}{c}+ \text { estructura de focalización } \\
\downarrow \downarrow\end{array}$} & \multirow[t]{2}{*}{ Conector justificativo } \\
\hline $\begin{array}{l}\text { Operador } \\
\text { intensificador }\end{array}$ & $\begin{array}{l}\text { Estructuras fijadas: lo que pasa } \\
\text { es que, lo que ocurre es que } \\
\text { (conector) / la verdad es que, lo } \\
\text { cierto es que (modal) }\end{array}$ & \\
\hline
\end{tabular}

20 Los hemos estudiado en otros elementos (Fuentes 2013b, 2013 en prensa). 
Su ámbito de actuación ocupa todos los planos macroestructurales:

Tabla 4:

\begin{tabular}{|c|c|c|c|}
\hline $\begin{array}{c}\text { Plano } \\
\text { INFORMATIVO }\end{array}$ & $\begin{array}{c}\text { Plano } \\
\text { ARGUMENTATIVO }\end{array}$ & $\begin{array}{c}\text { Plano } \\
\text { MODAL }\end{array}$ & $\begin{array}{c}\text { Plano } \\
\text { ENUNCIATIVO }\end{array}$ \\
\hline $\begin{array}{l}\text { - Focalización de una } \\
\text { estructura o término } \\
\text { - Progresión temática: } \\
\text { tras encapsulador } \\
\text { - Progresión temática: } \\
\text { y es que }\end{array}$ & $\begin{array}{l}\text { - Conector justificativo } \\
\text { - Intensificación asertiva } \\
\text { = elemento de fuerza } \\
\text { argumentativa } \\
\text { - Función argumentativa } \\
\text { cuando va con etiqueta }\end{array}$ & $\begin{array}{l}\text { - Enfatizador de la } \\
\text { modalidad }\end{array}$ & $\begin{array}{l}\text { - Enfatizador de } \\
\text { la enunciación }\end{array}$ \\
\hline
\end{tabular}

Es que constituye una estructura que proviene de la focalización, por tanto, es un procedimiento de estructuración de la información, pero también pone en juego la argumentación, la modalidad y la enunciación, estas últimas cuando focaliza elementos de estos planos: lo que está claro..., lo que digo es que... Argumentación y focalización van de la mano, ya que es que suele focalizar conclusiones o argumentos, coorientados (y es que) o antiorientados (pero es que, o con interrogaciones). Es un conector argumentativo cuando introduce justificaciones, $\mathrm{y}$ un operador intensificador cuando enfatiza un enunciado (o con si es que, pero es que, porque es que...).

En el plano informativo no sólo destaca el contenido de un segmento previo, cuyo contenido resalta, sino que entra en el juego de la progresión temática del texto focalizando etiquetas o encapsuladores, o bien elementos que aseguran la cohesión del texto. En otras ocasiones la progresión temática surge con la estructura y es que, tras un elemento genérico que se ilustra con un caso específico. En todos los casos el hablante muestra su jerarquización informativa, intensificando segmentos de contenidos o diseñando la partitura textual en el plano cohesivo, argumentativo o temático.

En el discurso parlamentario, caracterizado por la imposición de la opinión propia sobre los otros, es que actúa fundamentalmente como un mecanismo de intensificación. Por ello sus usos más abundantes son los de focalizador y operador intensificador.

La comparación con textos dialogales, monologales, escritos y orales, de diferente grado de formalidad, nos muestra su mayor frecuencia de empleo en la lengua oral y más si es coloquial. El operador intensificador aparece en textos de mayor cercanía comunicativa, donde la implicación del hablante es mayor, y sobre todo, en contextos polémicos. Conforme avanza la distancia, la formalidad, va desapareciendo su uso.

\section{OBRAS CITADAS}

Albelda Marco, Marta. 2007. La intensificación como categoría pragmática: Revisión y propuesta. Berne: Peter Lang.

Alcina, José y José Manuel Blecua. 1983. Gramática española. $4^{a}$ Edición. Barcelona: Ariel.

Arce Castillo, Ángela. 2006. El lenguaje político. Recursos pragmático-discursivos en registros formales e informales. Salamanca: Ratio Legis.

Bayley, Paul (Ed.). 2004. Cross-cultural Perspectives on Parliamentary Discourse. Amsterdam- 
Philadelphia: John Benjamins.

Blas Arroyo, José Luis. 2011. Políticos en conflicto: Una aproximación pragmático-discursiva al debate electoral cara a cara. Berne: Peter Lang.

Borreguero, Margarita. 2006. "Naturaleza y función de los encapsuladores en los textos informativamente densos (la noticia periodística)". Cuadernos de Filología Italiana 13: 73-95.

y Álvaro Octavio de Toledo. 2007. "Presencia y función de los encapsuladores en las crónicas periodísticas del s. xvii”. Philologia Hispalensis 21: 119-153.

Briz Gómez, Antonio. 1998. El español coloquial en la conversación. Esbozo de pragmagramática. Barcelona: Ariel.

, Salvador Pons y José Portolés. 2008-2015. Diccionario de partículas discursivas del español. Recuperado de http://www.dpde.com

Burguera, Joan. 2009. Gramática y pragmática de la interrogación retórica en español. Una aplicación al debate parlamentario. Tesis doctoral. Universidad de Barcelona, España.

Chilton, Paul y Christina Schäffner. 2002. Politics as Text and Talk. Analytics Approaches to Political Discourse. Philadelphia: John Benjamins. 2004. Analyzing Political Discourse. Theory and Practice. London: Routledge.

Domínguez García, Noemí. 2007. Conectores discursivos en textos argumentativos breves. Madrid: Arco Libros.

Ducrot, Oswald. 1984. El decir y lo dicho. Buenos Aires: Hachette.

Escandell, María Victoria. 1999. "Los enunciados interrogativos. Aspectos semánticos y pragmáticos”. En Bosque, Ignacio y Violeta Demonte (Dirs.), Gramática descriptiva de la lengua española. Madrid: Espasa. 3929-3992.

Fernández Leborans, María Jesús. 1992. “La oración del tipo: ‘es que...'. Verba 19: 223-239.

Fraser, Bruce. 1990. “An Approach to Discourse Markers”. Journal of Pragmatics 14.3: 383 95.

1996. "Pragmatic Markers". Pragmatics 6.2: 167-190.

1999. "What are Discourse Markers?". Journal of Pragmatics 31.7: 931-952.

2006. "Towards a Theory of Discourse Markers". En Fischer, Kerstin (Ed.), Approaches to Discourse Particles. Amsterdam: Elsevier. 189-204.

Fuentes Rodríguez, Catalina. 1987. Enlaces extraoracionales. Sevilla: Alfar. 1996. La sintaxis de los relacionantes supraoracionales. Madrid: Arco Libros. 1997. "Los conectores en la lengua oral: Es que como introductor de enunciado". Verba 24: $237-263$.

1999. La organización informativa del texto. Madrid: Arco Libros.

2003. "Operador/conector, un criterio para la sintaxis discursiva". Rilce 19.1: 61-85. 2009. Diccionario de conectores y operadores del español. Madrid: Arco Libros.

2013a. "La gramática discursiva: Niveles, unidades y planos de análisis". Cuadernos AISPI 2: 9-30.

2013b. "Adjetivos y adverbios intensificadores en el discurso parlamentario: Gramaticalización, argumentación y perspectiva de género". En Llamas, Carmen, Concepción Martínez y Manuel Casado (Eds.), Léxico y argumentación en el discurso público. Berne: Peter Lang. 73-103.

2013. "Intensification, Identity and Gender in the Andalusian Parliament". En prensa. 2015 [2000]. Lingüistica pragmática y análisis del discurso. $2^{a}$ Edición. Madrid: Arco Libros.

y Esperanza Alcaide. 2002. Mecanismos lingüisticos de la persuasión. Madrid: Arco Libros.

Garcés Gómez, María Pilar. 2008. La organización del discurso. Marcadores de ordenación y de reformulación. Madrid-Francfort: Iberoamericana-Vervuert.

Gili Gaya, Samuel. 1960. “Es que...? Estructura de la pregunta general”. Studia Philologia 
Homenaje ofrecido a D. Alonso II: 91-98.

Gómez Torrego, Leonardo. 1994. La impersonalidad gramatical: Descripción y norma. $2^{a}$ Edición. Madrid: Arco Libros.

González Ruiz, Ramón. 2009. “Algunas notas en torno a un mecanismo de cohesión textual: La anáfora conceptual”. En Penas, $\mathrm{M}^{\mathrm{a}}$ Azucena y Ramón González Ruiz (Eds.), Estudios sobre el texto: Nuevos enfoques y propuestas. Fráncfort del Main: Peter Lang. 247-278.

Gutiérrez Ordóñez, Salvador. 1986. Variaciones sobre la atribución. León: Universidad de León.

1997. Temas, remas, focos, tópicos y comentarios. Madrid: Arco Libros.

Herrero, Gema. 1992. "Las oraciones ecuacionales en español”. Verba 19: 201-222.

Ilie, Cornelia. 2001. "Unparliamentary Language: Insults as Cognitive Forms of Ideological Confrontation". En Dirven, René, Roslyn Frank y Cornelia Ilie (Eds.), Language and Ideology. Volume II: Descriptive Cognitive Approaches. Amsterdam-Philadelphia: John Benjamins. 235-263.

2003. "Histrionic and Agonistic Features of Parliamentary Discourse". Studies in Communication Sciences 3.1: 25-53.

2004. "Insulting as (un)Parliamentary Practice in the British and Swedish Parliaments:

A Rhetorical Approach”. En Bayley, Paul (Ed.), Cross-cultural Perspectives on Parliamentary Discourse. Amsterdam-Philadelphia: John Benjamins. 45-86.

Izquierdo, Dámaso y Ramón González Ruiz. 2013. "Encapsulación y etiquetas discursivas en el discurso parlamentario: Función argumentativa a partir de un corpus paralelo". Oralia 16: $185-219$.

Kovacci, Ofelia. 1991. "Sobre la estructura sintáctica de la forma de relieve ser + proposición relativa". Voz y Letra II.1: 39-49.

Loureda, Óscar y Esperanza Acín (Coords.). 2010. Los estudios sobre marcadores del discurso en español, hoy. Madrid: Arco Libros.

Martín Zorraquino, María Antonia y Estrella Montolío (Eds.). 1998. Los marcadores del discurso. Teoría y análisis. Madrid: Arco Libros.

y José Portolés. 1999. "Los marcadores del discurso". En Bosque, Ignacio y Violeta Demonte (Dirs.), Gramática descriptiva de la lengua española. Madrid: Espasa. 40514213.

Martínez, José Antonio. 1994. Cuestiones marginadas de gramática española. Madrid: Istmo.

Montolío, Estrella. 1999. " ¡Si nunca he dicho que estuviera enamorada de él! Sobre construcciones independientes introducidas por si con valor replicativo". Oralia 2: 37-69. 2000. Manual de escritura académica. Barcelona: Ariel.

Moreno Cabrera, Juan Carlos. 1982. “Atribución, ecuación y especificación: Tres aspectos de la semántica de la cópula en español". RSEL 12.2: 229-246. 1983. "Las perífrasis de relativo". Serta Philologica F. Lázaro Carreter I: 455-467. 1999. "Las funciones informativas: Las perífrasis de relativo y otras construcciones perifrásticas". En Bosque, Ignacio y Violeta Demonte (Dirs.), Gramática descriptiva de la lengua española. Madrid: Espasa. 4245-4304.

Mulder, Gijs. 1991. "Aproximarse y evitar: Estrategias de cortesía en castellano”. En Haverkate, Henk (Dir.), Foro Hispánico 2: Exploraciones semánticas y pragmáticas del español. Amsterdam: Atlanta. 69-79.

Navas Ruiz, Ramón. 1977. Ser y estar. El sistema atributivo del español. Salamanca: Almar.

Núñez Cabezas, Emilio y Susana Guerrero Salazar. 2002. El lenguaje político español. Madrid: Cátedra.

Pons, Salvador. 1998. Conexión y conectores. Valencia: Universidad de Valencia.

Porroche, Margarita. 1998. "Sobre algunos usos de que, si y es que como marcadores discursivos”. En Martín Zorraquino, María Antonia y Estrella Montolío (Eds.), Los marcadores del discurso. Madrid: Arco Libros. 229-242. 
Portero Muñoz, Carmen. 1997. Intensificación: Estudio de un clasema. Tesis Doctoral. Universidad de Córdoba, España.

Portolés, José. 1998. Marcadores del discurso. Barcelona: Ariel.

Real Academia Española. 2009. Nueva gramática de la lengua española. Madrid: Espasa.

Steel, Brian. 1991. A Textbook of Colloquial Spanish. $2^{\text {nd }}$ Edition. Madrid: SGEL.

van Dijk, Teun. 1983. La ciencia del texto. Barcelona-Buenos Aires: Paidós. . 2000. "Parliamentary Debates". En Wodak, Ruth y Teun van Dijk (Eds.), Racism at the Top. Parliamentary Discourses on Ethnic Issues in Six European States. Klagenfurt: Drava Verlag. 45-78.

2002. "Political Discourse and Political Cognition". En Chilton, Paul y Christina Schäffner (Eds.), Politics as Text and Talk. Analytics Approaches to Political Discourse. Amsterdam-Philadelphia: Benjamins. 203-239.

. 2004. "Text and Context of Parliamentary Debates". En Bayley, Paul (Ed.), Crosscultural Perspectives on Parliamentary Discourse. Amsterdam-Philadelphia: Benjamins. 339-372.

. 2005. "War Rhetoric of a Little Ally. Political Implicatures and Aznar's Legitimatization of the War in Iraq". Journal of Language and Politics 4.1: 65-91.

Vigara Tauste, Ana Mª 1994. Morfosintaxis del español coloquial. Madrid: Gredos. 